\title{
Teledetección y SIG, Herramientas de Gestión en la adaptación al Cambio Climático, Cuenca Alta del Río Goascorán, Honduras
}

Rafael Enrique Corrales Andino Vilma Lorena Ochoa López

\section{Resumen}

Honduras es el país con mayor área en el corredor seco, el 42\% del territorio y 213 municipios se encuentran ubicados en él, clasificándose la intensidad de sequía en grados bajo, alto y severo. En el caso particular de la Cuenca del Río Goascorán en Honduras, la mayor área es afectada por sequía grado alto, siendo los municipios de Aguanqueterique, Goascorán y Mercedes de Oriente, los potencialmente afectado por la sequía severa. En el país solo existe la clasificación con el método Pfafstetter de unidades hidrográficas de cuencas y subcuencas a nivel 1 y 2 , lo que dificulta la incorporación en nuevas políticas y tendencias de manejo de los recursos hídricos en forma regional estandarizada. Por lo que el establecimiento de políticas para el manejo y la gestión de los recursos naturales y particularmente los recursos hídricos para la adaptación al cambio climático, es necesario. Implementar una metodología con técnicas de análisis espacial (teledetección y Sistemas de Información Geográfica), que genere un aporte al país al presentar una clasificación ordenada de cuencas hidrográficas multiescalar, en subcuencas y microcuencas, pero también como intercuencas y cuencas cerradas o endorreicas, clasificadas por el tamaño o longitud del cuerpo de agua principal, estableciendo diferentes niveles (8 niveles) cada uno con usos de manejo establecidos. Al mismo tiempo, que contribuya a la generación de alternativas de abastecimiento y saneamiento de aguas como medidas de adaptación al cambio climático.

Palabras Clave: Pfafstetter, Cuencas, Río Goascorán, MDT, Honduras. 


\section{Astract}

Honduras is the country with the largest area in the dry corridor, $42 \%$ of the territory and 213 municipalities are located in it, being classified the intensity of drought in degrees low, high and severe. In the particular case of the Goascorán river basin in Honduras, the largest area is affected by high drought, with the municipalities of Aguanqueterique, Goascorán and Mercedes de Oriente being potentially affected by severe drought. In the country there is only the classification with the Pfafstetter method of hydrographic units of basins and sub-basins at levels 1 and 2, which makes it difficult to incorporate into new policies and trends in the management of water resources in a standardized regional form. So the establishment of policies for the management and management of natural resources and particularly water resources for adaptation to climate change, is necessary. To implement a methodology with techniques of spatial analysis (remote sensing and Geographic Information Systems), which generates a contribution to the country by presenting an orderly classification of multiscale basins, in sub-basins and micro-basins, but also as interbasins and closed or endorheic basins, classified by the size or length of the main water body, establishing different levels (8 levels) each with established management uses. At the same time, it contributes to the generation of water supply and sanitation alternatives as measures to adapt to climate change.

Keywords: Pfafstetter, Basin, Goascorán river, MDT, Honduras

Rafael Enrique Corrales Andino, (rcorrales@unah.edu.hn). Departamento de Ciencia y Tecnologías de la Información Geográfica, Facultad de Ciencias Espaciales, UNAH.

Vilma Lorena Ochoa López, (lorena.ochoa@unah.edu.hn). Departamento de Ciencia y Tecnologías de la Información Geográfica, Facultad de Ciencias Espaciales, UNAH.

Fecha de Recepción: 09 de marzo de 2017, fecha de aprobación: 04 de agosto de 2017. 


\section{INTRODUCCIÓN}

De acuerdo con la Comisión Centroamericana de Ambiente y Desarrollo en Centroamérica la sequía es cíclica y está relacionada con el período de El Niño, el cual en los últimos 60 años se ha incrementado (CCAD, 2010). Según el mapa del Corredor Seco Centroamericano (Figura 1), Honduras es el país con mayor área en el corredor seco, $42 \%$ del territorio y 213 municipios; así mismo el mapa clasifica la sequía en grados: bajo, alto y severo, y en el caso particular de la Cuenca del Río Goascorán en Honduras la mayor área es afectada por sequía grado alto, siendo los municipios de Aguanqueterique, Goascorán y Mercedes de Oriente los municipios potencialmente afectados por la sequía severa (Van deer Zee Areas, A. et al, 2012).
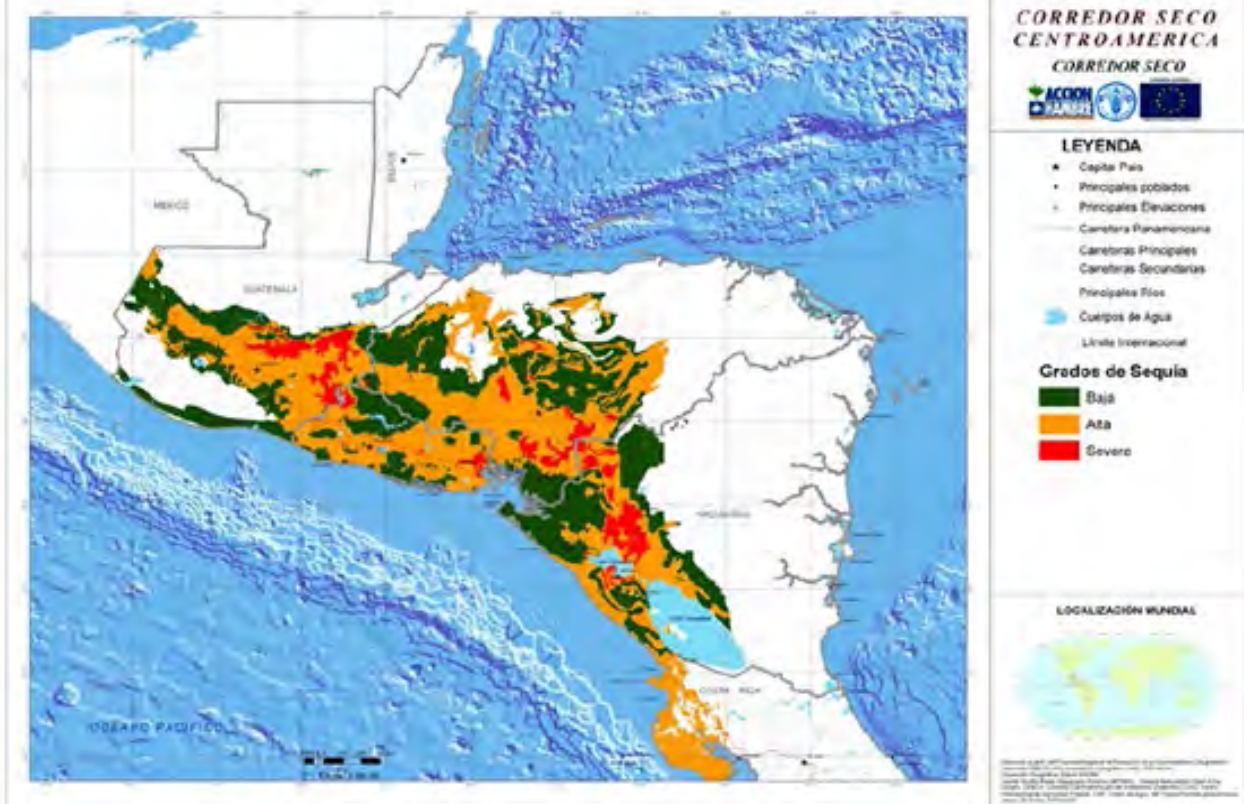

Figura 1. El Corredor Seco Centroamericano basado en meses secos $\times$ precipitación $\times$ Zonas de Vida de Holdridge (en blanco área fuera del corredor). Fuente: Van deer Zee Areas, A. et al, 2012.

A la zona alta de la cuenca del Río Goascorán pertenecen los municipios de Santa Ana, Opatoro, Guajiquiro, Mercedes de Oriente, Lamaní y Aguanqueterique, y las mancomunidades de: MAMLESIP, MANSURPAZ y MANSUCOPA. En esta zona los suelos están degradados, existen cárcavas y sedimentación de los cauces; 
numerosas familias sin servicios de agua potable teniendo efectos en la salud de las personas; hay problemas de pérdida de la cobertura natural, deslizamiento de los suelo y limitada cobertura de acceso al agua, debido a las prácticas de la deforestación y quema, uso inapropiado de la tierra y caminos sin mantenimiento, organización y dispersión de viviendas y vertidos de desechos sólidos y líquidos (PGCC, 2014).

En la cuenca alta del Río Goascorán no existe la delimitación de las unidades hidrográficas de subcuenca y microcuenca por niveles de jerarquización, importantes en establecimiento de políticas para el manejo y la gestión de los recursos naturales y particularmente los recursos hídricos para la adaptación al cambio climático. La base de este estudio es el mapa elaborado por el EROS DATA CENTER (USGS, 1997), tomando como base el Modelo de Elevación del Terreno GEOTOPO30, a nivel mundial. En este mapa el inicio de la delimitación fue continental, separando en el caso de América en Norte y Sur. Norte América se delimita para el nivel 1 en 9 cuencas, siendo la cuenca 9 la correspondiente a México y Centroamérica, la cual es una intercuenca. Por lo que, para nuestra región la primera codificación a nivel continental es 9 (Figura 2), y a nivel 2 siempre usando el mapa del USGS, la cuenca es 95 (Figura 3).

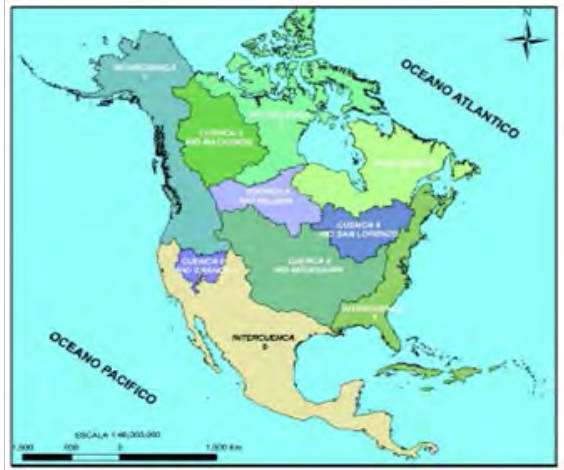

Figura 2. Delimitación Continental de la Cuenca de Norte América a nivel 1 , método de Pfafstetter. Fuente: MAGA, 2009.

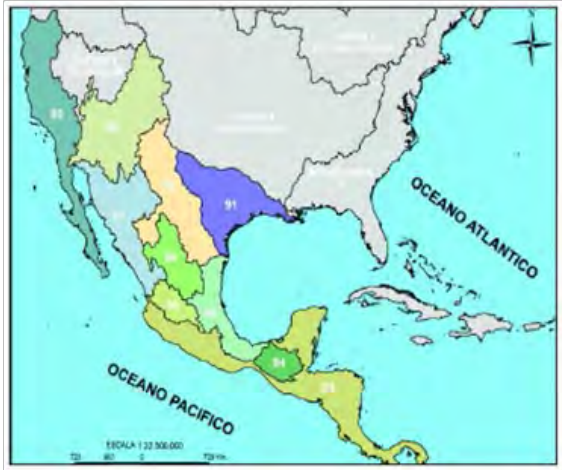

Figura 3. Delimitación Continental de la Cuenca de Norte América a nivel 2 , método de Pfafstetter. Fuente: MAGA, 2009. 
En Centroamérica, la metodología Pfafstetter se ha utilizado en la jerarquización de las cuencas hidrográficas de Guatemala, Nicaragua y El Salvador. De acuerdo con los resultados el número de cuencas hidrográficas delimitadas en cada país fue de ocho (8) en Guatemala, seis (6) en Nicaragua y siete (7) en El Salvador. El en máximo nivel de jerarquización identificado en la región, es nivel ocho (8) (MAGA, 2009; INETER, UNI, ANA, GIZ-PROATAS, 2014; Ministerio de Medio Ambiente y Recursos Naturales, 2016).

En Honduras no existe una clasificación a nivel 3 en adelante, por lo que será una gran oportunidad contar con el desarrollo de una delimitación siguiendo la metodología estandarizada por el USGS, a los niveles $4,5,6,7$, y 8 , permitiendo hacer estudios en unidades hidrográficas de cuenca, subcuenca y microcuenca.

\section{JUSTIFICACIÓN}

No existe la clasificación con el método Pfafstetter de unidades hidrográficas en el país, lo que dificulta la incorporación en nuevas políticas y tendencias de manejo de los recursos hídricos en forma regional estandarizada.

La investigación es pertinente porque da la oportunidad de abordar los problemas de abastecimiento y saneamiento de agua, utilizando las tendencias en políticas internacionales respecto al manejo de las unidades hidrográficas a diferentes niveles, con un sistema de clasificación de cuencas por jerarquía y el de áreas prioritarias, bajo criterios estandarizados a nivel global. Es relevante, porque abre las puertas para que tanto las instituciones nacionales como los organismos internacionales que trabajan el enfoque de manejo del recurso agua y la adaptación al cambio climático puedan incorporar la jerarquía de las unidades hidrográficas en las políticas y los planes de manejo de las cuencas.

La identificación de las Unidades hidrográficas a nivel regional, nacional y local, y particularmente en la cuenca alta del Río Goascorán, permite establecer niveles de manejo específicos de acuerdo a las características de cada zona, bajo mecanismos en un único lenguaje global. Asimismo, generar una base de datos geográfica para el apoyo a la gestión del conocimiento y de toma de decisiones respecto al manejo de los recursos hídricos a diferentes niveles. Además, permitirá identificar una cartera de proyectos de manejo integrado de la cuenca y la adaptación al cambio climático, sujetos a ser financiados por organismos internacionales, para beneficio 
de las diferentes comunidades que habitan en las unidades hidrográficas del área de estudio.

De manera general el objetivo de la investigación fue adaptar una metodología con técnicas de Sistemas de Información Geográfica y Percepción Remota, que sirvan para el análisis de las unidades hidrográficas de la cuenca alta del Río Goascorán, como herramienta de gestión de los recursos naturales e hídricos en la adaptación al cambio climático.

\section{MARCO CONCEPTUAL}

Sistemas de Información Geográfica (SIG): Estos se manejan en base a dos modelos uno vectorial y otro ráster, este último tiene que ver con las imágenes digitales, las cuales se pueden definir como un arreglo matricial de filas y columnas con unidades mínimas cartografíales, llamadas celdas o píxeles. El concepto de celda en una malla ráster es equivalente al de píxel, en el campo de las imágenes digitales, pero con la diferencia que representan una porción de terreno dentro de un sistema de coordenadas específico. Una particularidad más de las imágenes digitales es la composición por bandas espectrales, y cada valor recogido indican la reflectancia por unidad de longitud de onda, dependiendo de cómo se encuentre diseñado el sensor, así tendrá un número de bandas o capas (Olaya, 2012).

Teledetección: Se define como cualquier medio de observación remota, que involucra los procesos de adquisición de las imágenes digitales y su posterior tratamiento (Chuvieco, 2002 citado por Corrales y Ochoa, 2016). También es definida como una técnica de carácter multidisciplinario que permite adquirir imágenes de la superficie terrestre desde sensores instalados en plataformas espaciales, mediando un mecanismo de transporte de energía electromagnética, natural o artificial (Hernández y García, 2014 citado por Corrales y Ochoa, 2009).

Modelo de Digital de Terreno (MDT): Un MDT se define como un conjunto de datos numéricos que describe la distribución espacial de una característica del terreno según Doyle, 1978. El principal producto de la Shuttle Radar Topography Mission SRTM, son los Modelos Digitales del Terreno, los cuales son una categoría de modelos simbólicos que ha nacido y se ha desarrollado al amparo de las nuevas tecnologías de la Percepción Remota con dispositivos aérotransportables.

El MDT, se deriva de la misión Shuttle Radar Topografy Mision (SRTM), que obtiene datos de elevación a escala global generando una base de datos completa de 
la tierra cercana a una alta resolución digital. La SRTM consistió en un sistema de radar especialmente modificado que voló a bordo del transbordador espacial Endeavour durante una misión de 11 días en febrero de 2000. La SRTM fue un proyecto internacional liderado por la Agencia Nacional de Inteligencia Geoespacial (NGA), NASA, la Agencia Espacial Italiana (ASI) y el Centro Aeroespacial Alemán (DLR). Hay tres salidas de resolución disponibles, incluyendo resoluciones de 1 kilómetro, 90 y 30 metros para el. La Global Land Cover Facility GLCF sirve las principales ediciones de United Stated Geological Survey USGS, además ha 'mejorado' ediciones así como ofrece ediciones de mosaico WRS-2 para aproximarse a escenas del Sensor Landsat.

Existen dos tipos de modelos; los digitales y los analógicos y su diferencia reside en que los primeros son una codificación cifrada, lo que permite su tratamiento por medios informáticos 0 análisis digital de imágenes ADI, y para alcanzar la elaboración de los modelos digitales se necesita, por tanto, efectuar un proceso de codificación de la información, que permite una representación virtual en forma de cifras. Las relaciones espaciales o las características que se desean representar se traducen a diferentes tipos de estructuras numéricas de las cuales las más comunes son vectores, matrices, conjuntos, etc. 0 expresiones matemáticas que representan relaciones topológicas y funcionales.

Una maqueta, como modelo icónico, también constituye un modelo analógico de la realidad o terreno MAT, en el que se da una especial importancia a la conservación de las proporciones o relaciones espaciales relativas. Un mapa convencional es otro modelo analógico más sofisticado en el que se establecen unas relaciones especiales de simbolización que permiten la abstracción de una realidad tridimensional a un modelo plano.

Los MDT pueden ser construidos directamente a partir de la realidad que representan, siendo más habitual que exista un modelo analógico intermedio a partir del cual se realiza la codificación. Éste puede adoptar formas diversas, desde los mapas, hasta pares fotográficos estereoscópicos. Por este motivo, los MDT han sido entendidos como una versión digital (y por tanto codificada) de los mapas convencionales por lo que, en ocasiones, han sido denominados mapas virtuales (Moellering, 1983).

Sin embargo, Doyle es de la opinión que un simple listado secuencial de cotas pueda ser considerado un modelo digital de elevaciones. Así mismo, es necesario realizar alguna limitación en cuanto al tipo de variable representada ya que es 
discutible que las versiones digitales de los mapas temáticos tales como mapas de vegetación, mapas de infraestructura vial o de puntos singulares puedan ser considerados modelos digitales del terreno. Por lo que en la actualidad la tendencia es a considerar únicamente a una estructura interna que represente las relaciones espaciales entre los datos, y que la variable representada en el modelo debe ser cuantitativa y de distribución continua. De esta manera se excluyen las variables temáticas, y las variables representadas por entidades lineales o puntuales (por ejemplo, una red hidrológica).

Para describir la altimetría de un área mediante un conjunto de pisos altitudinales, a través de los MDT, se utiliza una representación llamada MDE o modelo digital de elevaciones. Así mismo siguiendo la analogía cartográfica, es posible construir un conjunto de modelos derivados, elaborados a partir de la información contenida explícita o implícitamente en el MDE.

Todo dato al ser obtenido por dispositivos remotos (teledetección), es susceptible de revisión mediante el contraste o verificación del modelo derivado con el objeto real. Este contraste se realiza mediante métodos de análisis del error que, habitualmente, se basan en la comparación de una muestra extraída del modelo derivado con medidas empíricas realizadas sobre el terreno. Los resultados del análisis del error permiten efectuar ajustes en el algoritmo, aumentando su fiabilidad y, por tanto, su capacidad predictiva. Esto significa que un algoritmo sólidamente construido, aplicado sobre un MDT fiable, permite estimar propiedades que pueden ser aplicadas al objeto real con márgenes moderados de error, aportando información difícil de obtener por otros medios (Figura 4).

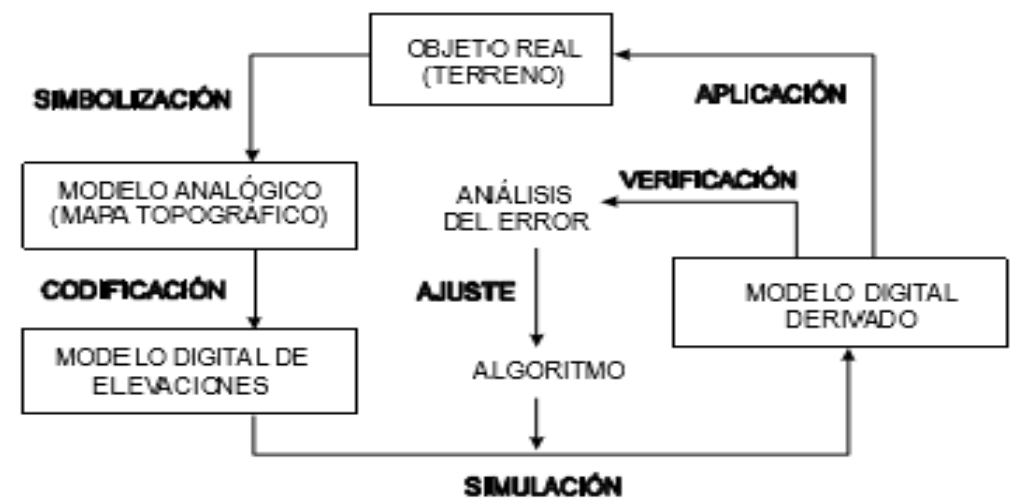

Figura 4. Procesos de un MDE. Fuente: Felicísimo, 1994. 
Uno de los aspectos del análisis de imágenes, es la posibilidad de poder trabajar un análisis digital de imágenes 0 análisis visual de imágenes, posibilitando la facilidad de uso o manejo referente a obtener información de forma rápida y sencilla por parte de los usuarios. El acceso a la información impresa en un mapa o desplegada en pantalla es sencillo ya que se realiza directamente mediante unos conocimientos cartográficos más o menos profundos, lo que dependerá de la experiencia del experto.

El acceso a los MDT es mucho más complejo pues se realiza a través de equipos informáticos cuyo manejo, mediante una serie de instrucciones específicas, obliga a un entrenamiento especializado. Idealmente, los conocimientos cartográficos necesarios para la interpretación de los mapas convencionales deben complementarse con otros relativos a proceso de imágenes, bases de datos, teledetección y programación de software, lo que implica un considerable esfuerzo de educación suplementario (Felicísimo, 1994).

Entre las características que diferencian los Modelos Analógicos de Terreno MAT de los MDT en los aspectos prácticos del uso de la información, tal como lo vemos en la Tabla 1.

Tabla 1. Características del MAT y del MDT.

\begin{tabular}{|c|c|c|}
\hline Propiedad & Modelo Analógico del Terreno & Modelo Digital del Terreno \\
\hline Manejo & Sencillo & Compleja \\
\hline Estabilidad & Baja & Alta \\
\hline Transportabilidad & Alta & Baja \\
\hline Actualización & Compleja & Sencilla \\
\hline Tratamiento numérico & Dificil & Fácil \\
\hline Simulación & No & Si \\
\hline
\end{tabular}

Fuente: Felicísimo, 1994.

La Transportabilidad de los MDT está estrechamente vinculada a los equipos informáticos que los manejan: por un lado, la información sólo es accesible en los locales 0 instituciones donde estos equipos están ubicados físicamente; por otro lado, el intercambio de la información entre diversos equipos no está completamente resuelto. En lo referente al primer caso, los equipos no suelen ser 
transportables por lo que existe una separación entre el trabajo de campo y la integración de la información que puede ser limitante en algunos aspectos. Por otro lado, el intercambio de información depende del formato de almacenamiento de los sistemas informáticos. En este sentido, la tendencia general es hacia la compatibilización (más que la estandarización) y en la actualidad este tipo de problemas suele resolverse con relativa facilidad.

La actualización de los datos es teóricamente inmediata en los MDT a través de los sistemas informáticos que los manejan. Los cambios en los datos básicos pueden realizarse de una forma directa, y para la reelaboración de los datos derivados basta con ejecutar de nuevo los programas ya elaborados. Este tipo de manejos es, al contrario, muy costoso en los mapas convencionales debido a que la producción de un nuevo documento obliga a la repetición de etapas intermedias menos automatizadas y depende de procesos de artes gráficas de coste económico muy alto.

Algunas posibilidades que ofrecen los MDT, dependientes del tratamiento numérico de los datos, resultan impracticables con los mapas convencionales debido a la naturaleza analógica de los mismos. Entre ellas está la capacidad de obtener estadísticos descriptivos o la creación de nueva información mediante el tratamiento numérico de uno o más modelos precedentes. Un ejemplo de la primera posibilidad es la obtención de la altitud media de una serie de zonas del mapa. La distribución de pendientes en función de la altitud es un ejemplo de la segunda. La obtención de ambos resultados a partir de un mapa convencional exige un laborioso tratamiento manual sujeto a un alto riesgo de error y con baja repetibilidad. En los MDT es necesaria la realización de programas que realicen esta función (sencillos en este caso particular, aunque la complejidad pueda ser mucho mayor en otros problemas). Una vez hecho este esfuerzo inicial, la amortización es previsiblemente muy rápida si el método es de validez general. Los errores, si el MDT está suficientemente depurado, son inexistentes y la repetibilidad es absoluta. Finalmente, Felicísimo (1994) describe literalmente que los MDT permiten realizar procesos de simulación del funcionamiento de un sistema dinámico real.

Manipulando los datos del MDT o complementándolos con otras descripciones de fenómenos físicos se accede a un medio de investigación de gran potencialidad. El método reside en establecer los principios físicos de fenómenos que dependen más o menos estrechamente de las propiedades del terreno y realizar una simulación numérica a partir de estos principios teóricos. Por este camino pueden elaborarse 
modelos de previsión de fenómenos de interés y, si se tiene la posibilidad de confrontar los resultados con la realidad, se hace posible el perfeccionamiento del modelo mediante ajustes sucesivos.

Método Pfafstetter. Ha sido reconocido por la United States Geological Survey (USGS, EE.UU), quienes realizaron la delimitación y codificación de cuencas hidrográficas al nivel mundial con el apoyo de las Naciones Unidas, vía UNEP (United Nations Environment Programme). La tendencia actual es que este método sea un estándar internacional de delimitación y codificación de cuencas hidrográficas. El sistema está siendo adoptado por algunos países sudamericanos como Bolivia, Brasil y Perú (Cabral Antúnez, 2011). Provee una única identificación para cada cuenca en función de su red de drenaje de las cuencas, y consiste en asignar códigos a las unidades hidrográficas con base a la topología de la superficie del terreno (UICN, SENAGUA, SGCAN,2009).

Diseño de alternativas de abastecimiento. Permite el pre-diseño de una red de abastecimiento dibujando sus componentes sobre el mapa, desde el punto de captación hasta la red de distribución. Permite calcular parámetros hidráulicos, económicos y otros (Varela, F., et al. 2013).

\section{MARCO METODOLÓGICO}

La investigación tuvo un enfoque cuantitativo de tipo descriptivo, debido a la delimitación de las unidades hidrográficas que se centró en la aplicación de un Modelo Digital del Terreno (MDT) y sus derivados, y una etapa de Diseño de Necesidades de Abastecimiento y Saneamiento de Agua, que se centran en parámetros biofísicos (mediciones de caudal, la presión del agua, características de las tuberías y velocidad del agua).

El tipo de estudio fue deductivo, el cual buscaba establecer relaciones de validez general independientes, tomando en cuenta las condiciones de observación. También fue una investigación aplicada: ya que el principal objetivo se basó en resolver problemas prácticos: la definición de una metodología geoespacial para resolver problemas en la falta de jerarquización en las unidades hidrográficas a diferentes escalas, hasta llegar a la subcuenca alta del Río Goascorán. 


\section{RESULTADOS METODOLÓGICOS}

Diseño del Sistema de Información Geográfica y obtención de variables derivadas del MDT.

Para poder trabajar los diferentes niveles de codificación en la jerarquía de la cuenca, se descargaron y desplegaron 53 imágenes ráster en formato BIL (Figura 5), correspondiente a la conformación de la base de datos geográfica, y los preparativos del análisis geoespacial, iniciando con la filtración de los datos rasterizados, específicamente al llenado de vacíos o datos de valor cero en la imagen (Figura $6)$, los que de no corregirse producirían errores en los subsiguientes productos derivados como: Dirección, Acumulación, Stream y Cuencas de Captación.

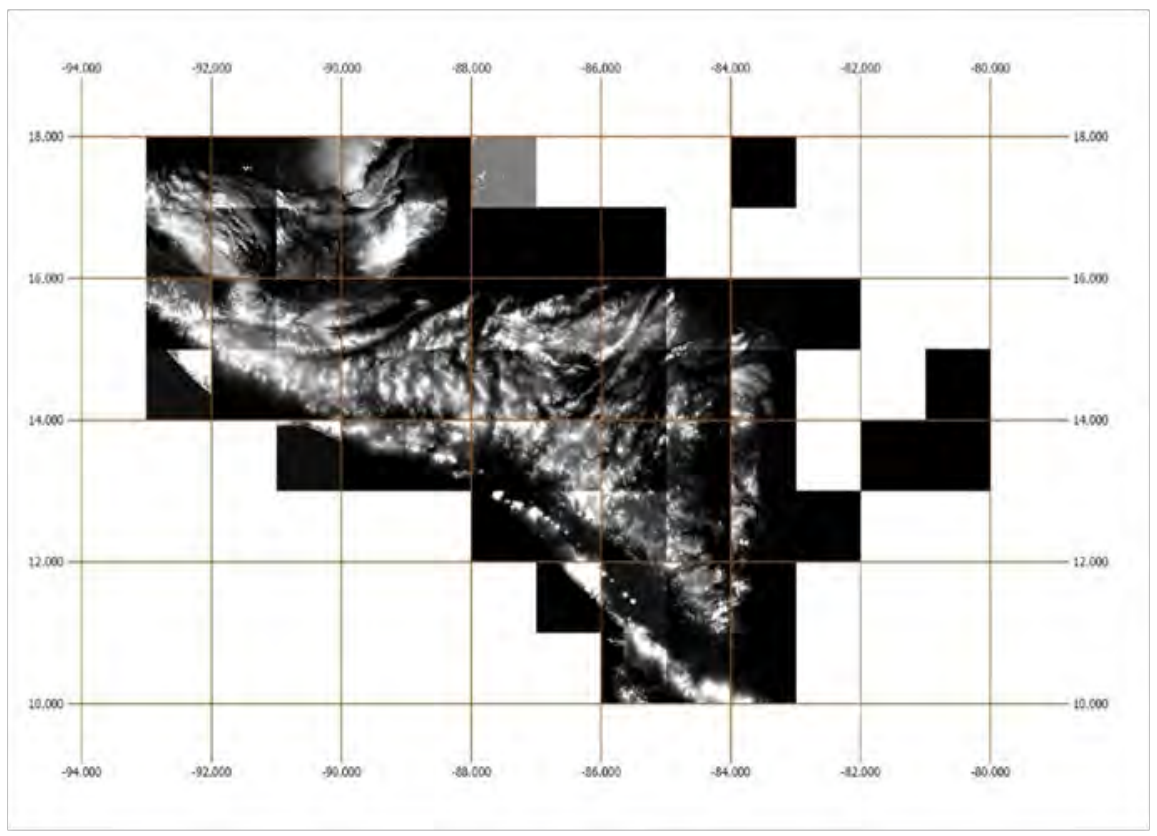

Figura 5. Mosaico de MDT, Centroamérica. (Elaboración propia). 


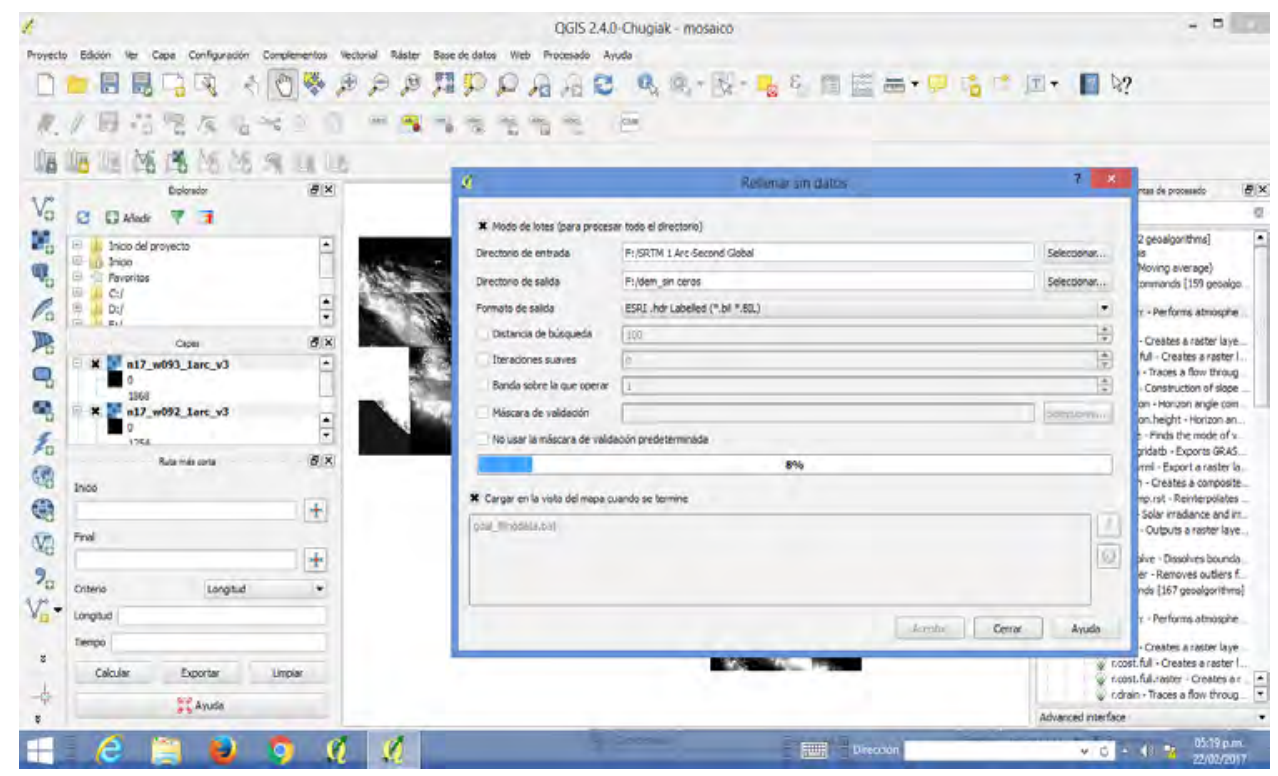

Figura 6. Eliminación de ceros del MDT. (Elaboración propia).

Jerarquización de las unidades hidrográficas por el Método de Pfafstetter.

Los resultados metodológicos de la jerarquización (Tabla 2), indican que, entre las mejores formas de aplicar la teledetección, es con análisis de datos con modelación a partir de los diferentes algoritmos derivados de fórmulas utilizadas en los ambientes técnico científico de sensores remotos, específicamente en las áreas de tratamiento digital de imágenes, para el cálculo del río principal, en función del criterio de área drenada, lo que discrimina entre río principal y tributarios.

Se delimitan las cuatro cuencas principales, prevaleciendo el criterio de área de drenaje, posteriormente se delimitan las intercuencas, desde el punto de desembocadura de cada cuenca hacia la margen opuesta del río principal, hasta hacer contacto con otro límite de cuenca. Para la Subcuenca de Goascorán, los resultados de la delimitación respecto a la región nacional fueron de cuatro áreas, donde identificamos una codificación de 95736, identificando las unidades hidrográficas de Palagua, Rancho Grande, San Juan y Goascorán. 
Tabla 2. Jerarquía de Cuencas del Método Pfafstetter.

\begin{tabular}{|c|c|c|c|c|c|c|c|}
\hline Variable & $\begin{array}{l}\text { Definición } \\
\text { Conceptual } \\
\text { de la } \\
\text { Variable5 }\end{array}$ & $\begin{array}{l}\text { Definiciôn } \\
\text { Operacional } \\
\text { de la Variable }\end{array}$ & Dimensiones & Indicadores & $\begin{array}{l}\text { Unidad } \\
\text { de } \\
\text { analisis }\end{array}$ & Items & $\begin{array}{l}\text { Instrumento } \\
\text { a Utilizar }\end{array}$ \\
\hline Subcuenca & $\begin{array}{c}\text { Una } \\
\text { subcuenca } \\
\text { es un área } \\
\text { que no } \\
\text { recibe } \\
\text { drenaje de } \\
\text { ninguna otra } \\
\text { área }\end{array}$ & \multirow{3}{*}{$\begin{array}{l}\text { Delimitación } \\
\text { de las } \\
\text { unidades } \\
\text { hidrográficasa } \\
\text { nivel } 7 \text { y } 8 \text { del } \\
\text { Método } \\
\text { Pfafstetter }\end{array}$} & $\begin{array}{c}\text { Las cuatro } \\
\text { unidades tipo } \\
\text { cuenca se } \\
\text { codifican con } \\
\text { los digitos } \\
\text { pares } 2,4,6 \text { y } \\
8 \text {, desde } \\
\text { aguas abajo } \\
\text { hacia aguas } \\
\text { arriba. }\end{array}$ & $\begin{array}{l}\text { Numero de } \\
\text { Cuencas } \\
\text { delimitadas y } \\
\text { codificadas }\end{array}$ & $\begin{array}{l}\text { La } \\
\text { unidad } \\
\text { hidro- } \\
\text { lógica a } \\
\text { nivel } 7 y \\
8\end{array}$ & $\begin{array}{l}\text { Cuerpos } \\
\text { de Agua }\end{array}$ & $\begin{array}{c}\text { Programa } \\
\text { SIG, MDT, } \\
\text { Hojas } \\
\text { Cartográicas } \\
\text { escala } \\
1: 50,000 \\
\text { GPS }\end{array}$ \\
\hline Intercuenca & $\begin{array}{l}\text { Una } \\
\text { intercuenca } \\
\text { lo recibe de } \\
\text { otras } \\
\text { unidades } \\
\text { aguas arriba }\end{array}$ & & $\begin{array}{c}\text { Las cuatro } \\
\text { unidades tipo } \\
\text { intercuenca se } \\
\text { codifican con } \\
\text { los digitos } \\
\text { impares } 1,3,5 \text {, } \\
7 \text { y } 9 \text {, también } \\
\text { desde aguas } \\
\text { abajo (desde } \\
\text { la confluencia). }\end{array}$ & $\begin{array}{l}\text { Numero de } \\
\text { Intercuencas } \\
\text { delimitadas y } \\
\text { codificadas }\end{array}$ & $\begin{array}{c}\text { La } \\
\text { unidad } \\
\text { hidro- } \\
\text { lógica a } \\
\text { nivel } 7 \text { y } \\
8\end{array}$ & $\begin{array}{l}\text { Cuerpos } \\
\text { de Agua }\end{array}$ & $\begin{array}{c}\text { Programa } \\
\text { SIG, MDT, } \\
\text { Hojas } \\
\text { Cartográicas } \\
\text { escala } \\
1: 50,000 \\
\text { GPS }\end{array}$ \\
\hline $\begin{array}{l}\text { Cuenca } \\
\text { Cerrada }\end{array}$ & $\begin{array}{c}\text { Una cuenca } \\
\text { cerrada es } \\
\text { un área de } \\
\text { drenaje que } \\
\text { no } \\
\text { contribuye } \\
\text { con flujo a } \\
\text { otra unidad o } \\
\text { cuerpo de } \\
\text { agua, tales } \\
\text { como un } \\
\text { océano o } \\
\text { lago }\end{array}$ & & $\begin{array}{c}\text { La cuenca } \\
\text { cerrada de } \\
\text { código } 3 \text {, se } \\
\text { subdivide en } \\
\text { las unidades } \\
\text { de tipo cuenca } \\
\text { de códigos } 32 \text {, } \\
34,36 \text { y } 38 \text { y } \\
\text { en las } \\
\text { unidades tipo } \\
\text { cuenca } \\
\text { cerrada } 31,33 \text {, } \\
35,37 \text { y } 39 .\end{array}$ & $\begin{array}{l}\text { Numero de } \\
\text { Cuencas } \\
\text { internas } \\
\text { delimitadas y } \\
\text { codificadas }\end{array}$ & $\begin{array}{l}\text { La } \\
\text { unidad } \\
\text { hidro- } \\
\text { lógica a } \\
\text { nivel } 7 \text { y } \\
8\end{array}$ & $\begin{array}{l}\text { Cuerpos } \\
\text { de Agua }\end{array}$ & $\begin{array}{c}\text { Programa } \\
\text { SIG, MDT, } \\
\text { Hojas } \\
\text { Cartográficas } \\
\text { escala } \\
1: 50,000 \\
\text { GPS }\end{array}$ \\
\hline
\end{tabular}

Fuente: Elaboración propia. 


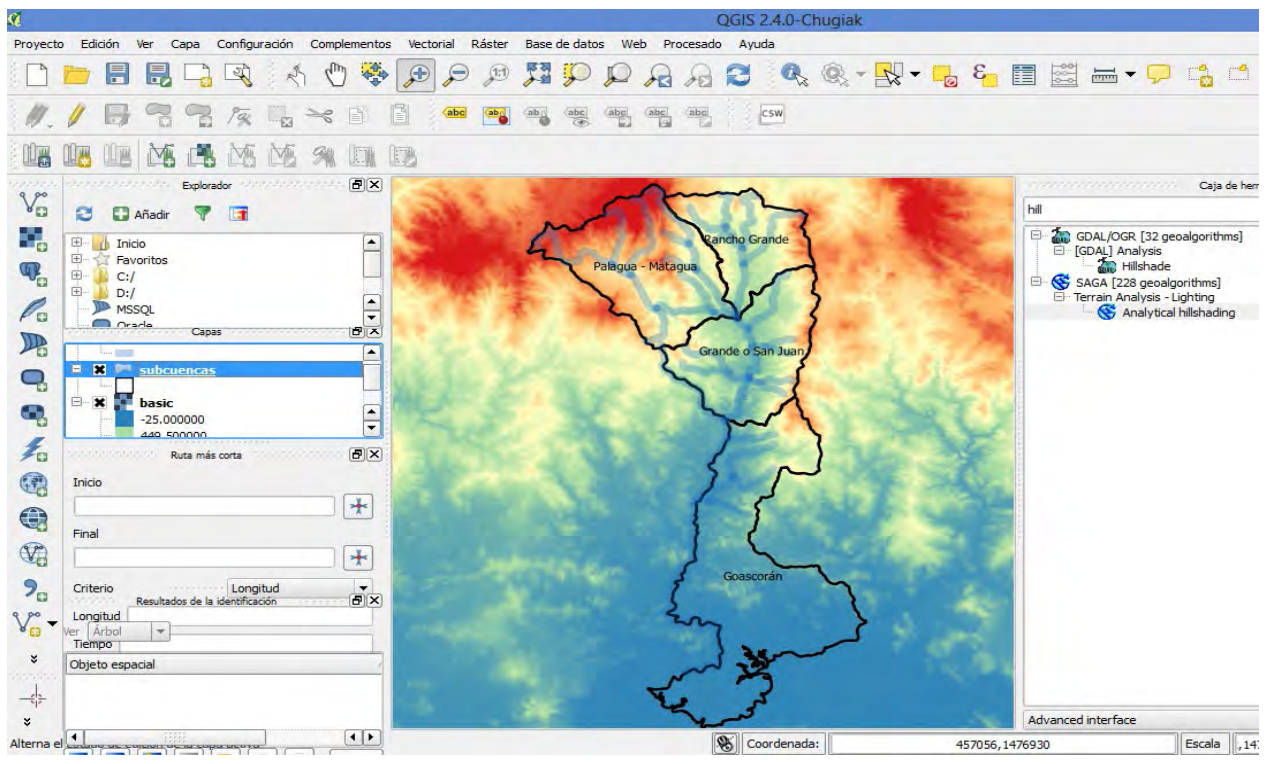

Figura 7. Unidades hidrográficas de la subcuenca del río Goascorán (Elaboración propia).

Se codifican las cuencas e intercuencas resultantes de la primera subdivisión, se pueden subdividir de la misma manera, de modo que la subdivisión de la cuenca 8 genera las cuencas (números pares) por ejemplo: $82,84,86$ y 88 y las intercuencas (números impares) por ejemplo: 81, 83, 85 y 89. Los dígitos de la subdivisión se agregan al código de la unidad que está siendo dividida. Los elementos a considerar en la codificación son: en regiones de litoral, el sentido de la codificación será horaria; en vertientes orientales la codificación será de norte a sur; y en vertientes occidentales las cuencas se codificarán de sur a norte. La Tabla 3, muestra los niveles de jerarquización y codificación de una cuenca hasta alcanzar el nivel 8. 
Tabla 3. Niveles de Codificación por jerarquía de la cuenca.

\begin{tabular}{|l|l|}
\hline Niveles & Código \\
\hline Nivel 1 & 9 \\
\hline Nivel 2 & 95 \\
\hline Nivel 3 & 951 \\
\hline Nivel 4 & 9517 \\
\hline Nivel 5 & 95178 \\
\hline Nivel 6 & 951781 \\
\hline Nivel 7 & 9517813 \\
\hline Nivel 8 & 95178130 \\
\hline
\end{tabular}

Fuente: Ministerio de Agricultura, Ganadería y Alimentación, 2009.

Bajo esta metodología, las unidades de drenaje son divididas en tres tipos: intercuencas, subcuencas y cuencas cerradas o endorreicas. Una subcuenca es un área que no recibe drenaje de ninguna otra área. Una intercuenca lo recibe de otras unidades aguas arriba. $Y$ una cuenca cerrada es un área de drenaje que no contribuye con flujo a otra unidad o cuerpo de agua, tales como un océano o lago.

Aparte del conocimiento previo de los afluentes del área de estudio, es importante cumplir con las siguientes reglas que determinan la ubicación de las confluencias:

a) El primer punto de unión del río principal con un tributario seleccionado previamente deberá ser el de los territorios 1, 2 y 3.

b) El punto de unión del río principal con el segundo tributario previamente seleccionado, aguas arriba, deberá ser el de los territorios 3,4 y 5 .

c) El punto de unión del río principal con el tercer tributario seleccionado, aguas arriba, será el de los territorios 5, 6 y 7 .

d) El punto de unión (más alta al interior de la cuenca), del rio principal con el cuarto tributario seleccionado, aguas arriba, deberá ser el de los territorios 7 , 8 y 9.

Para explicar el orden y jerarquización de las subdivisiones de un territorio que llamaremos unidades hidrográficas, cumpliendo con las reglas antes mencionadas se muestra la Figura 8, de no cumplirse las reglas es posible desplazar o modificar la ubicación de las confluencias a las intersecciones al río principal con otros tributarios hasta que las reglas de ubicación se cumplan. 
La investigación se desarrolla en dos etapas. En la primera etapa se delimito la Subcuenca Guajiquiro y en la segunda etapa la Subcuenca Paneaguara-Cimarrón. El trabajo en cada subcuenca implico tres grandes fases.

Fase 1: Generación de la Geodatabase, en la cual se diseñó el SIG con base al MDT, los datos levantados en campo y las variables derivadas del MDT.

Fase 2: Definición de las Unidades Hidrográficas, aplicando la metodología Pfafstetter se delimitó y codificó las unidades hidrográficas en las subcuencas. Además, se realizó la caracterización biofísica de cada una de las unidades.

Fase 3: La socialización y validación de resultados, esta permite validar con los beneficiarios y actores claves las Unidades hidrográficas y los mecanismos de adaptación al cambio climático.

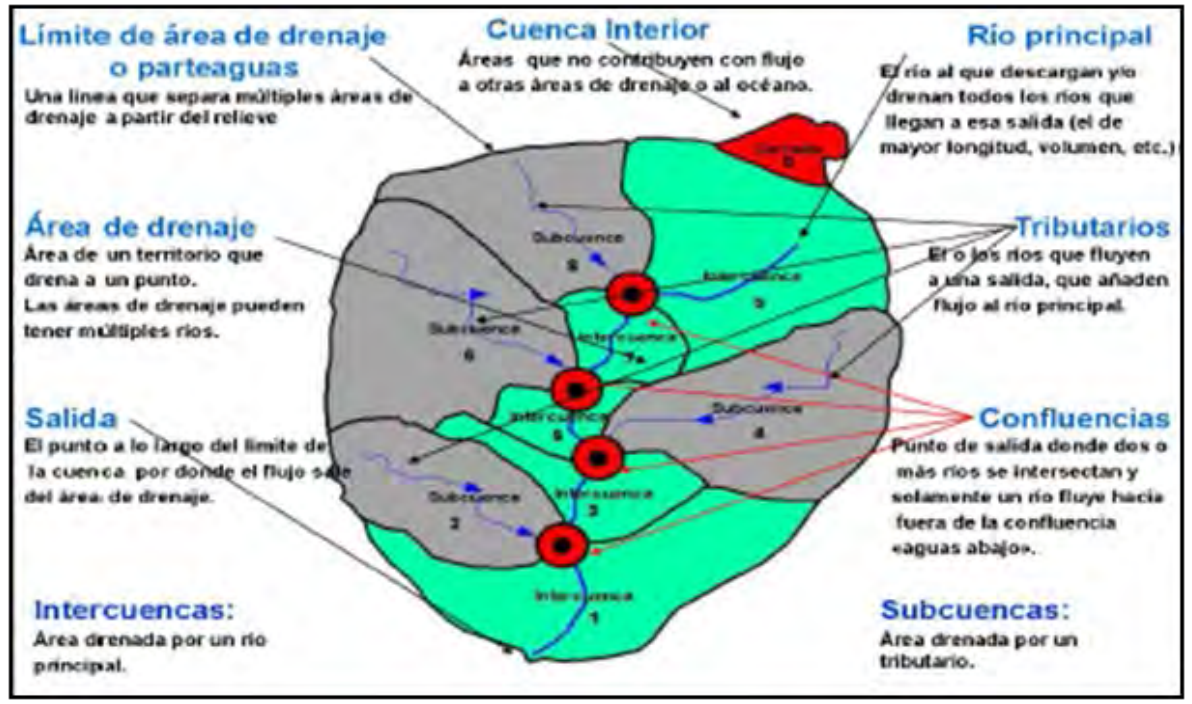

Figura 8. Descripción esquemática de las reglas de codificación de unidades hidrológicas.

Fuente: Valencia, s/a.

Alternativas de abastecimiento y saneamiento de agua.

El Diseño de alternativas de abastecimiento, permite el diseño de una red de abastecimiento dibujando sus componentes sobre el mapa, desde el punto de captación hasta la red de distribución. Permite calcular parámetros hidráulicos (como las presiones en la tubería), económicos (como la cuota a satisfacer 
por la comunidad para la sostenibilidad del sistema diseñado) y otros (como el dimensionamiento de los bombeos). Sin embargo, conviene aclarar que la aplicación no está pensada para la fase de planificación y priorización de las actuaciones, por lo que para abordar la fase constructiva sería realizar una carpeta técnica más detallada.

Acceso a datos: A base de una capa de acceso a datos por encima de la propia del software base empleado, que combina un sistema de almacenamiento en shapefile con una base de datos local de tipo SQLite (Varela Garcíaet al, 2009). Esto implica un cambio en la infraestructura del software libre para realizar un desacoplamiento en el acceso a los datos de modo que los nuevos desarrollos se pudieran ajustar a diferentes entornos geográficos.

Extracción de información: Desde la aplicación la cual deriva de la extensión llamada gvSIG FONSAGUA, desarrollada por CartoLab de la Universidad da Coruña, en Galicia, España, y adaptada para su utilización en la Cuenca Alta del Rio Goascorán, se puede generar automáticamente el informe de diagnóstico (información más relevante y necesidades de la comunidad) y el informe de alternativas (información técnica referida a la viabilidad, coste y características de las alternativas). Existe además la posibilidad de exportar a formatos editables una serie de consultas predefinidas sobre los datos y un resumen del presupuesto. Otra opción es la de abrir un diálogo que aglutina datos de diagnóstico y de las alternativas que afectan a las comunidades para poder hacer comparaciones y priorización.

\section{DISCUSIÓN}

Una de las acciones que deben tomarse en cuenta cuando se intentan avances considerables en la gestión y manejo de cuencas, con enfoque a una Adaptación al Cambio Climático (ACC), es haber identificado las bases para establecer métodos que permitan ubicar los proyectos que aseguren esta ACC, es por ello que las herramientas de teledetección y de SIG, son consideradas las más apropiadas aplicaciones de escritorio para planificación y manejo, con una debida validación de campo que establezca el ordenamiento territorial del uso del suelo según las capacidades de la división administrativa y biofísica de una cuenca hidrográfica.

En importante reconocer que se pueden producir limitaciones en los procesos cartográficos derivados de los geodatos digitales, tales como los Modelos Digitales del Terreno (MDT), si a estos no se les aplica las correcciones metodológicas adecuadas para el trabajo específico, en este caso la derivación de cuencas 
hidrográficas, se generará con baja precisión. Es este estudio se seleccionó el método de clasificación de cuencas hidrográficas Pfafstetter, que permite comparar a diferentes escalas, y a la vez a trascender de la escala nacional, ya que diferentes organismos internacionales tienen políticas que requieren la información en esta clasificación en específico con orden y codificación única para cada país.

\section{CONCLUSIONES}

La aplicación de esta metodología generará un aporte al país al presentar una clasificación de orden multiescalar de la clasificación de cuencas hidrográficas, en subcuencas y microcuencas, pero también como intercuencas, subcuencas y cuencas cerradas o endorreicas, clasificadas por el tamaño o longitud del cuerpo de agua principal, estableciendo diferentes niveles (hasta 8 niveles) cada uno con usos de manejo establecidos, en este caso a través de la categoría del grado de sequía.

Por otra parte, el diseño de alternativas de abastecimiento, permite que los tomadores de decisiones locales (juntas de agua y municipalidades) puedan tener las bases de una red de abastecimiento dibujando sus componentes sobre el mapa y que está a la vez pueda generarles reportes muy aproximados a valores monetarios del costo de las obras, lo que proyectará las necesidades en caso de requerir aumentar una red de abastecimiento por crecimiento poblacional, o porque la fuente hídrica inicial presente déficit en su producción, de esta manera se pueden estudiar las diferentes alternativas que se sumarían a la red de abastecimiento original.

\section{BIBLIOGRAFÍA}

- Cabral Antúnez, N. 2011. Criterios Técnicos de Delimitación y Codificación de Cuencas, Caso Específico Región Oriental del Paraguay. Secretaria del Ambiente. Dirección General de Protección y Conservación de los Recursos Hídricos. Asunción, Paraguay. Consultado en http://www.siagua.org/sites/ default/files/documentos/documentos/Informe_Cuencas_Hidrograficas_ Nestor_Cabral_Antunez.pdf. 27 de noviembre de 2015.

- CCAD. 2010. Estrategia Regional de Cambio Climático. pag 95. 
- Corrales Andino, R.E., V. L. Ochoa López. (2016). Cálculo de reflectancia en imágenes LandSat OLI-8, sobre la región central de Honduras, mediante software libre SEXTANTE. Revista Ciencias Espaciales, Vol.9, No.1 Primavera. ISSN:2225-5249. Pp 81-96.

- Doyle, F.J. 1978. Digital terrain models: and overview. Photogrammetric ingeneering and remote sensing. 44(12:1481-1485). Consultado en www. academia.edu/2807451/modelos_digitales_de _terreno.

- Felicísimo, A. (1994). Modelos Digitales del Terreno. Introducción y Aplicación en Ciencias Ambientales. Consultado en el 2016.https://www.researchgate.net/ publication/232423519.

- INETER, UNI, ANA, GIZ-PROATAS. 2014. Cuencas Hidrográficas de Nicaragua bajo la metodología Pfafstetter. Managua, Nicaragua. Consultado en: http:// www.ana.gob.ni/DocumentosSiAGUA/slideshow/Album $\% 20$ Cuencas $\% 20$ Nic\%20Revisado.pdf. 15 de enero de 2016.

- Ministerio de Agricultura, Ganadería y Alimentación. 2009. Mapa de Cuencas Hidrográficas a escala 1:50,000, República de Guatemala, Método de Pfafstetter. Unidad de Planificación Geográfica y Gestión de Riesgo. 63 pp. Consultado en: http://web.maga.gob.gt/wp-content/blogs.dir/13/files/2013/ widget/public/memoria_cuencas_50000.pdf. 20 de noviembre de 2015.

- Ministerio de Medio Ambiente y Recursos Naturales.2016. Plan Nacional de Gestión Integrada del Recurso Hídrico. El Salvador. Consultado en:http:// dialogoelsalvador.com/dialogo_sv/admin/uploads/documentos/galerias/bb703plan-nacional-de-gestin-integrada-del-recurso-hdrico-de-el-salvador-resumeejecutivo.pdf .02 de agosto de 2017.

- Moellering, H. (1983): "Designing interactive cartographic systems using the concepts of real and virtual maps". En Clarke, K.C. (1990:5).

- Olaya, V. 2012. Sistemas de Información Geográfica. Consultado en: www. creativecommons.org.http://wiki.osgeo.org/wiki/Libro_SIG. 12 de septiembre de 2014.

- Programa de Gestión Comunitaria de Cuencas (PGCC) bajo una perspectiva de contribución a la Adaptación al Cambio Climático y la Reducción de Riesgos a Desastres en el Corredor Seco de Honduras Departamento Federal de Asuntos 
Exteriores DFAE, Agencia Suiza para el Desarrollo y la Cooperación COSUDE. 2014. Primera Fase 2014 - 2017. Tegucigalpa, Honduras.

- UICN-SUR, Secretaria Nacional del Agua (SENAGUA), Secretaria General de la Comunidad Andina (SGCAN). (2009). Informe de delimitación y codificación de unidades hidrográficas del Ecuador, escala 1:250,000nivel 5 metodología Pfafstetter. Quito, Ecuador. http//aplicaciones.senagua.gob.ec/descargas/ archivos/delimitación-codificación-Ecuador.pdf. 27 de noviembre de 2015.

- Valencia Barrero, E. s/a. Metodología de delimitación y codificación de Otto Pfasftetter. http://cuencagrijalva.ecosur.mx/cuenca_grijalva/files/informe_Final/ sp03_archivos/03_0735_cap_33_delimimitacion_cuenca.pdf. 15 de enero de 2016.

- Van deerZeeAreas,et al. 2012. Estudio de caracterización del corredor seco centroamericano. (Países - CA-4). Tomo 1. AFS, FAO, ECHO. Consultado en: http://reliefweb.int/sites/reliefweb.int/files/resources/tomo_i_corredor_seco.pdf. 25 de septiembre de 2015.

- Varela García, F.; Nuñez López, M.; PugaAlonso F. et al. 2013. PCI FONSAGUA. Una experiencia de cooperación interuniversitaria basada en los Sistemas de

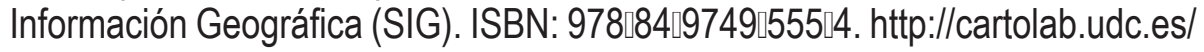
pcifonsagua/PCl - FONSAGUA

- Varela García, J. I., TsaoSantín, F., Molejón Quintana, C., Estévez Valiñas, J., \& Varela García, A. (2009). Desarrollo en gvSIG para la mejora de la gestión de información de ISF en Honduras. Jornadas Internacionales de gvSIG. Valencia. 